part of the book deals with the effects of temperatures on spin systems, and consequently the thermodynamics and statistical mechanics of magnetism are considered. Phase transitions and the Ising model are discussed at length. Tables for indirect exchange theory form a very useful appendix and the book concludes with a complete and up-to-date bibliography of collateral reading.

Magnetism is far from all theory, and this is clearly emphasized in the Physics of Magnetism. A general and fully comprehensive review of magnetism is presented with an emphasis on physical concepts. One departure from common practice is the use throughout of the MKSA system of units, although the treatment is as nonmathematical as possible. The book begins with a classification of magnetic substances and then describes the properties of a ferromagnetic body. Theoretical background for the origin of magnetism and the theories for ferromagnetism and ferrimagnetism form the second part of the book. The discussion tends to be pictorial, and the reader needs little in the way of quantum mechanics. The book is centred around magnetic domains, and a fully comprehensive discussion of this concept is given with numerous figures and photographs. The domain concept is extended to account for the various observed magnetization processes, and many detailed results and conclusions are presented. More specialized topies form the last part of the book-some of the more important topics discussed are induced magnetic anisotropy, the ferromagnetism of thin films, thin wires and fine particles, various magnetiza tion phenomena, the rare earth metals and also techniques for investigating internal magnetic structure. Probably the most important aspect of magnetism concerns its technological application, and this is not forgotten with a brief discussion of the types of magnetic materials and special applications of them. Data relating to magnetic substances are collected in an appendix.

In my own opinion, both books are most successful in their intending aims. The Theory of Magnetism is intended for the research worker, and caters particularly for the theoretician. The major achievement is to step from most complicated situations to accurate arguments with simple explanations only. The style of the book is unconventional and many topies are presented in a textbook for the first time. Physics of Magnetism is pitehed on a somewhat less-advanced level as it caters for undergraduates as well as research workers. For an experimentalist, it contains most of the important facts appertaining to magnetism and contains lucid explanations for them. Both contain numerous problems for the reader to test his knowledge and its applications. There is little material common to both books and together they cover most of the field of magnetism. They are both attractively presented and may be recommended with confidence.

$$
\text { C. A. BAtes }
$$

\section{ANALYSIS OF SURFACE-ACTIVE AGENTS}

Identification and Analysis of Surface-active Agents by Infrared and Chemical Methods

By Prof. Dieter Hummel. Translation by Dr. E. A. Wulkow. Text Volume. Pp. xiv +386 . Spectra Volume. Pp. 166 (466 spectra). (New York and London: Interscience Publishers, a Division of John Wiley and Sons, Inc., 1964.) 150s. the two volumes.

DROF. HUMMEL'S work on the systematic identifica.

tion of surface-active agents from their infra-red spectra was reported at the third International Congress of Surface Activity in 1960. His book, first published in German in 1962, contains a much expanded version of his own work as well as chemical methods for the identification of surfactants, which were added in order to broaden the analytical character of the book.
Identification and Analysis of Surface-active Agents by Infrared and Chemical Methods is the translation, without modification, of the earlier book and hence the literature is covered only to 1960. In the area of detergent analysis, as in most other fields of research, progress has been notable and rapid in the past 5 years, and thus much of the content of the book is out of date. For example, gas liquid chromatography is mentioned only once and thinlayer chromatography not at all. For this reason, the book fails in the author's expressed intention of providing a general book on detergent analysis. It remains, however, an extremely important reference volume for the detergent analyst and will be particularly useful in the identification of little-known actives.

A comprehensive list of surfactants (or 'tensides' as the author proposes all interfacially active materials should be called) is reviewed systematically with copious notes on methods of manufacture, physical properties and infra-red spectra. This chapter (141 pages) and the volume of spectra form the useful content of the book. The introductory chapters on structural characteristics of surfaceactive agents (13 pages) and the determination of the electrochemical behaviour of surface-active agents (12 pages) are oversimplified and contain a number of errors. For example, the cationic character of amine oxides in aqueous solution is ascribed to the formation of free amine by hydrolysis. In fact the cationic species present is the conjugate acid of the amine oxide.

The later chapters on chemical methods for determining the structural characteristics of tensides (24 pages) and methods for the quantitative analysis of tensides (37 pages) suffer most from the omission of recent research. This is unfortunate since there is no good modern review of the analysis of mixtures of surfactants which can aid the detergent analyst.

The tables at the end of the book (114 pages) summarize much of the information given in the text. Most of them are useful but one should question the value of recording in tables the results of ompirical tests (for example, the Wurzschmitt reaction with iodine) which cannot be used with confidence for the identification of specific materials.

The volume of spectra is well produced and peak positions and intensities are easily read direct from the figures. The text volume is printed in Times Roman type on good quality paper and both volumes are well bound. The translation is adequate but suffers from literal translation in parts. The lack of typographical errors in the whole work is notable. The book costs $£ 710 s$. which, combined with the lack of new information it contains, will provent its use in all oxcept specialist laboratorics.

\section{P. ROBSON}

\section{LEATHER ANALYSIS AND TESTING \\ The Chemistry and Technology of Leather}

Edited by Fred O'Flaherty, William T. Roddy and Robert M. Lollar. Vol. 4: Evaluation of Leather. (American Chemical Society Monograph Series, No. 134.) $\mathrm{Pp}$, viii +440 . (New York: Reinhold Publishing Corporation; London: Chapman and Hall, Ltd., 1965.) 17.50 dollars; $144 s$.

THE publication of Volume 4 of the American Chemical Society Monograph Series No. 134, The Chemistry and Technology of Leather, completes the Series begun with the appearance of Volume 1 in 1956. As in the previous volumes, each chapter is contributed by one or more authorities in the particular field, but in this volume all the authors have been drawn from the United States. Included in the volume are the analysis and assessment of raw materials and finished leather, including physical test methods. A valuable chapter on fungal resistance of leather has been contributed by T. C. Cordon of the Fastern Regional Laboratory of the U.S. Department of 